\title{
Arbor
}

\section{El dolor y lo sagrado}

\section{Andrés Tornos Cubillo}

Arbor CLXXI, 676 (Abril), 653-663 pp.

En este trabajo no se trata del dolor mismo, sino de cómo se ha planteado el problema del dolor en relación con la experiencia de lo sagrado, entre personas y grupos que sufrían. Se recuerdan primero algunos hechos que tienen que ver con esta relación y luego se desarrolla lo que estos hechos sugieren: el dolor es un destino que nos sitúa en la perspectiva de nuestra mortalidad y finitud, y solamente en la elaboración libre de este límite se da la verdadera aceptación del mundo de Dios. En relación con lo sagrado el dolor marca sagradamente y crea un destino. Esto es lo importante.

En el prólogo a su libro Problems of Suffering in Religions of the World, J. Bowker comenta que el sufrimiento sería antes un hecho de la vida que un problema de la mente ${ }^{1}$. Como hecho de vida vendría a ser el mismo en todos los tiempos y en todos los sitios, pero como problema no. Porque la forma como el sufrir se hace problema para la mente dependería de los valores religiosos con los que en una u otra forma choca el sufrir, y esos valores religiosos son diferentes, al menos por lo que respecta a judíos, cristianos, musulmanes, hindúes y budistas. En el sufrimiento no habrá por tanto un mismo problema para estas cinco religiones, aunque el sufrimiento como hecho de vida sea el mismo para todos los creyentes e increyentes.

Esto en nuestro ambiente cultural suena a juego de palabras, porque estamos acostumbrados a decirnos que el problema es el sufrimiento mismo, no la manera de vivirlo y elaborarlo mentalmente. Pero esto no sería exacto. Quien no piensa no tiene problemas, aunque sufra, porque el plantear problemas y luchar con ellos es una actividad de la mente. 
Con esto doy un primer paso para aclarar que en este trabajo no voy a tratar del dolor mismo, sino de cómo se ha planteado el problema del dolor, en relación con la experiencia de lo sagrado, entre personas y grupos que sufrían.

Pero me parece necesario dar un paso más. Y es observar que hoy en la cultura de occidente, desde la cual y en el interior de la cual pensamos, damos por supuesto que el problema del dolor está sencillamente en que el dolor existe. Por ello entendemos que la manera humanamente correcta de resolver el problema del dolor sería esforzarse lisa y llanamente por suprimirlo. De otros puntos de vista, por ejemplo de los religiosos, aceptamos que puedan darnos explicaciones suplementarias útiles para aliviarnos, para encontrar sentido, para motivarnos en orden a luchar más eficazmente contra el dolor, etc. Pero encontraríamos desacertado e incluso inhumano que alguien pretendiera en nombre de alguna fe, ante una situación de dolor, que el problema puede no estar en que hay dolor y en que la gente sufra, sino quizás en alguna otra cuestión.

Quiero insistir en que no podríamos discurrir tal como discurrimos, o sea, entendiendo que el problema del dolor está en el hecho mismo de que el dolor existe, si no tuviéramos un particular concepto de la existencia humana que se ve cuestionado y desafiado por la presencia del dolor. $\mathrm{Si}$ entendiéramos de otra forma la existencia, el dolor de todos modos nos haría sufrir, por supuesto. Pero el problema del dolor, el conjunto de interrogantes que brotarían de la experiencia del sufrimiento o del contacto con él, no irían desde luego en la misma dirección ni apelarían a las mismas soluciones. Eso es lo que nos llevan a pensar las reflexiones de Bowker arriba recogidas.

Serviría para ejemplificar estas ideas el conocido pasaje de «Los Hermanos Karamazov» de Dostoievsky, en el cual Ivan y su hermano Aliosha discuten sobre el problema del mal y la existencia de Dios. Impresiona la fuerza con que Iván, en ese pasaje, hace presentes a su hermano los males y sufrimientos del mundo; también quizá la sincera ingenuidad con que éste, a pesar de tomar muy en serio los horrores de que le habla su hermano, responde confiadamente sobre su fe y su vivir. Diré entre paréntesis que ha sido para mí la repetida consideración de este texto lo que me ha llevado siempre de nuevo a repensar el tema de las relaciones entre el dolor y lo sagrado, de las cuales quiero tratar aquí. Pues bien: lo especial que siempre he encontrado de nuevo en las palabras de Aliosha es que ellas expresan una manera enormemente lógica de vivir el mal y el dolor desde una existencia llena de lo sagrado. Ésta, penetrada de agradecimiento a Dios por un don de la vida vivido como santo, reacciona de una manera totalmente distinta que el modo de ser representado 
por Iván, forzado siempre a justificar su vivir y el todo de la vida. Y es notorio que los dos, en el punto de partida, se refieren a los mismos dolores; pero desde luego los problemas a que responden son completamente diferentes. Ivan padece el problema teórico del dolor: cómo es que puede existir el sufrimiento si existe Dios; cómo ha de entenderse la vida una vez que se reconoce en ella la presencia constante del sufrimiento. Para Aliosha el problema es práctico: cómo vivir los sufrimientos que uno padece y cómo ayudar a quienes sufren, si uno acata y adora a Dios y experimenta una infinita gratitud por el don de la vida.

Hecha esta larga introducción recordaré primero algunos hechos que tienen que ver con la relación entre el dolor y la experiencia de lo sagrado, por lo demás sobradamente conocidos, comentándolos en cada caso muy brevemente. En segundo lugar desarrollaré algo más detenidamente lo que me sugieren esos hechos.

\section{Hechos}

1. La experiencia de lo sagrado se presenta muchas veces como dolorosa y sin embargo fascinante.

Este carácter doloroso de las experiencias de lo sagrado es algo un tanto enigmático, que se nos hace presente en narraciones de diversos pueblos. Virgilio en el libro VI de la Eneida (vv. 42ss.) nos describió de modo impresionante a una joven pitonisa que se retuerce con el cabello erizado al aproximarse el Dios; sin duda se hace eco, al escribir así, de muchas formas de percibirse en el mundo mediterráneo la experiencia de lo sagrado. Mucho más cercanos a nosotros son los textos de Santa Teresa al referir su experiencia de transverberación o de San Juan de la Cruz en el Cántico Espiritual, cuando llama llaga y herida a lo que han dejado en él los encuentros con lo divino (estrofas 1, 7, 9, etc.).

2. La experiencia de lo sagrado suscita muchas veces y en muchas culturas la necesidad de entrar por caminos de dolor.

Mucho más documentadas todavía están en muchos pueblos las prácticas de asumir dolor o incluso provocárselo para renovar o profundizar la experiencia de lo sagrado. Hallamos estas prácticas con un grado refinadísimo de codificación entre los bámbara de Africa, pero en el mismo continente es universal la apelación a sacrificios y sufrimientos cuando se trata de sacralizar, mediante alguna clase de iniciación, una época de 
la vida o una función importante en la convivencia social. Esto último estuvo también generalizado entre los pieles rojas de América del Norte, hasta poderse decir que sin apelación al sufrimiento no se concibe modo alguno de dar forma sólida a la vida de las personas. Pero también en Asia los budistas e hinduistas apelan a muchos modos de ascesis para avanzar hacia la realidad última del propio ser, y en la tradición cristiana distintas escuelas de espiritualidad profesan el mismo convencimiento. No me resisto a transcribir un trozo del comentario que añade San Juan de la Cruz al verso de su estrofa 35 del Cántico Espiritual que dice «Entremos más adentro en la espesura»:

« O si se acabase ya de entender cómo no se puede llegar a la espesura de sabiduría y riquezas de Dios si no es entrando en la espesura del padescer de munchas maneras puniendo en eso el alma su consolación y desseo y cómo el alma que de ueras desea sabiduría, dessea primero de veras entrar más adentro en la espesura de la cruz, que es el camino de la vida por el que pocos entran! Porque dessear entrar en espessura de sabiduría, y riquezas y regalos de Dios es de todos: más dessear entrar en la espesura de trauajos, y dolores por el hijo de Dios, es de pocos».

Algo muy semejante podríamos encontrar en Santa Teresa, de quien es el conocido dicho: «Señor, o padecer o morir», o en el mismo San Ignacio de Loyola.

3. En muchos pueblos la vinculación entre el dolor y lo sagrado adquiere vigencia social: se generan entonces ritos, mitos, prácticas y formas compartidas de discurrir que dan forma a la convivencia.

Poco añadimos si decimos que esta vinculación entre experiencia de lo sagrado y sufrimiento, vividos por personas especialmente dotadas para lo místico, no ha sido en muchas sociedades algo carente de repercusión social y exclusivamente propio de individuos singulares. Todo lo contrario: como hace ver lo que hemos recordado de las ceremonias de iniciación en Africa y en la antigua América del Norte, se ha institucionalizado socialmente en muchos pueblos una fuerte conexión entre el sufrimiento voluntario y la cimentación sagrada de la vida. Y todavía más: de la participación iniciática en estos ritos espectacularmente dolorosos, donde los había, parecen haberse irradiado hacia el vivir cotidiano formas de discurrir que hacían valorar como cosa natural el arrostrar sin miedo y sin repugnancia los trabajos o sufrimientos que a uno podrían sobrevenirle. Hasta el punto de que en tales pueblos tendía a despreciarse a las personas y grupos sociales que no se mostraban capaces de tanta fortaleza. 
También ha existido entre nosotros el sentir popular que ha compartido esas tendencias, inclinánose a menospreciar como blandos y «afeminados», según la clásica expresión que hoy resulta tan incorrecta, a quienes no sabían sobrellevar con tranquila entereza los dolores e infortunios que a cualquiera pueden sobrevenirle.

4. Cuando en el dolor se hace presente la experiencia de lo sagrado, el modo de proceder inducido por el dolor se transforma.

Quiero con esto decir algo que, dada la escasez de mi información, no sé documentar bien con datos de la antropología y de la historia de las religiones. Sí he hallado, por ejemplo, que Goldammer, en su obra Formenwelt des Religiösen ${ }^{2}$, enumera entre las conductas específicamente propias de los místicos, documentables en muy distintas culturas, el silencio frente al dolor: un silencio de adoración en que culminaría la actitud ante el misterio. Los ejemplos que él pone los toma del libro de Job $(2,13)$, de Isaías $(53,7)$ y de sabios chinos e indios. Yo encuentro pobres sus expresiones si las comparo, por ejemplo, con lo que conocemos de las cartas de san Francisco Javier o con referencias que yo mismo he podido recoger de personas que vivían como un inestimable don de Dios lo que habían experimentado con ocasión de tremendos sufrimientos personales y familiares. He comprobado sin lugar a dudas que el dolor, cuando se padece en estrecha conexión con experiencias de lo sagrado, no sólo da lugar a actitudes de profunda adoración, sino que también induce reacciones de agradecimiento, exaltación del sentimiento del propio valer y reorientación radical y positiva de la vida.

5. El dolor llama a juicio a las evocaciones de lo sagrado y hace que se profundicen o se desmientan.

Esto no hace falta documentarlo más, pues cada uno de nosotros conoce muchos casos concretos de ello. El dolor es una tentación de escándalo contra la posibilidad y la verdad de toda relación con lo sagrado, y lo que hallamos sobre ello en los salmos o en Job ha ocurrido en todos los tiempos y en todas las partes del mundo.

\section{Reflexiones}

Cuando uno empieza a reflexionar sobre estos hechos, por todos conocidos, algo salta a la vista de entrada: lo lejos que está de ellos la so- 
ciedad de hoy. Sin duda que esas formas de ver la relación entre el dolor y lo sagrado, o sea, el dar por supuesto que la experiencia de lo sagrado será dolorosa y sin embargo desearla, el atribuir en muchas ocasiones un valor positivo al sufrimiento, el verlo como clave de diversas formas de dignidad y de status sociales estimados..., todo eso ahora mayoritariamente se tendría por antihumano o absurdo, y desde luego por inadecuado para construir una sociedad sana.

Esta postura actual suele considerarse además tan evidente que prácticamente nunca se ve la necesidad de justificarla. Ello aparecería con claridad en el hecho de que, repitiéndose muchas veces aquí y allá que es obligación social primaria el procurar aliviar los sufrimientos de otros y expresándose frecuentísimamente muy duras críticas contra aquellos que desatenderían a esa obligación (vg. los países más desarrollados, los individuos de clases sociales dominantes), a pesar de todo nunca se intenta fundamentar ni lo primero, la obligación moral de aliviar el sufrimiento de otros, ni lo segundo, la legitimidad de criticar a quienes no lo hacen. Y es que se vería como totalmente superfluo aclarar algo que se encuentra clarísimo.

Pero otro contraste se aprecia entre los hábitos culturales de hoy y los representados por los hechos que antes enumeré, el cual podría resultarle a uno más curioso todavía. Y es que aquellos hechos antes enumerados siempre implican de alguna forma un modo internamente activo de sufrir uno sus propios dolores. Y en cambio la cultura actual del dolor mira a éstos como desde fuera y como a algo a lo cual hay que combatir mirando hacia afuera de quienes padecen; en concreto hacia las causas de los sufrimientos, de modo que, vencidas éstas, el remedio recaiga sobre quien sufre como viniendo desde fuera. $\mathrm{Al}$ menos eso es lo que aparece en las muchas reflexiones que se intercambian y escriben acerca del sufrimiento: se ocupan mucho de las causas físicas, sociales y políticas del dolor, pero no de lo que las personas harían activamente con sus propios dolores. Como si esto segundo no tuviera interés, o no mereciera la pena que se gastaran palabras en ello, o fuera tabú.

Cuando organizaba las presentes reflexiones confieso que me entró curiosidad acerca de esto último, y que busqué con algún empeño materiales en que aparecieran los razonamientos compartidos y los lugares comunes a que en nuestra cultura se recurriría para decir algo a quien sufre sobre cómo asumir bien el dolor, principalmente cuando no puede escapar a él. Mi empeño resultó casi inútil. Incluso en los escritos redactados desde perspectiva creyente los razonamientos y lugares comunes que nos salen al paso se refieren prácticamente siempre a tres temas: insistir en que un cristiano debe tomar conciencia sinceramente de lo terriblemente que 
se sufre en nuestro mundo; ponderar la obligatoriedad y grandeza que tiene el comprometerse en la lucha contra ese sufrimiento; y analizar la responsabilidad personal y social que algunos pueden tener en los muchos sufrimientos de otros ${ }^{3}$. Sobre la posibilidad de hallar sentido en el sufrir y de enriquecerse con él apenas he encontrado un estudio dedicado al bello libro de V. Frankl «Un Psicólogo en el Campo de Concentración» ${ }^{4}$ y dos trabajos: uno conmovedor de E. Kübler-Ross, la iniciadora del interés por los enfermos terminales, sobre el sufrimiento vivido y el sufrimiento comercializado ${ }^{5}$, y otro de Karl Rahner, muy olvidado por cierto, que lleva el título de «Pasión y Ascesis. Sobre la Fundamentación Filosófico-Teológica de la Ascética Cristiana»6.

Luego volveré sobre este último, pero ni él ni los otros textos nombrados tienen la representatividad cultural de las reflexiones que se construyen con razonamientos compartidos y lugares comunes.

Esquemáticamente podría decirse por tanto que, para habérselas con el dolor, nuestro mundo occidental no conoce ni acepta otros recursos que guerrear indirectamente contra él combatiendo a sus causas objetivas. Con las personas concretas que están sufriendo no sabemos del todo qué hacer, sino eso, irnos de ellas hacia los diagnósticos, los tratamientos y las campañas. Y en esta concepción la experiencia de lo sagrado sólo puede figurar de dos modos: o bien como una de las causas externas del dolor, en tanto que cultivadora de dolorismos o conducente a formas de vida desviadas de los correctos planteamientos de una vida bien organizada para su mejor calidad; o también como remedio y causa exterior de alivio, entendida de manera más o menos supersticiosa. En la primera perspectiva lo indicado sería, por supuesto, extirpar esa forma dañina de experiencia religiosa; pero incluso en la segunda el hombre sufriente se vería sólo llevado a conducirse de modo pasivo con respecto a una posible ayuda de la divinidad, después de haber intentado propiciársela.

Este silencio de los pensadores, de los teólogos y de las conversaciones cotidianas sobre cómo uno podría encontrar sentido en el dolor resulta más incongruente cuando la narrativa literaria y el periodismo sensacionalista tanto se complacen en abordar casos de masoquismo. Se sabe de sobra que con el dolor pueden hacerse muchas cosas, además de pasarlo mal, y para ello no hacen falta grandes conocimientos de psicopatología. Pero es ya ilustrativo el detalle de que estas cuestiones se localicen justamente, casi siempre, en el campo de lo patológico. Como si tuviera que ser a la fuerza cosa perversa el querer hacer algo con el dolor que uno sufre.

Si de nuevo intentáramos explorar las razones por las cuales nuestra cultura moderna tiende a encontrar perversos los intentos de utilizar el 
dolor para un mayor desarrollo o cualificación de uno mismo, de nuevo nos hallaríamos con que no se siente la más mínima necesidad de explanarlas o buscarlas. Lo mismo que se encuentra evidente la obligación moral de luchar contra el sufrimiento de otros, se encuentra evidente que el intentar ver valores en algún sufrimiento es dolorismo, o sea perversión. El que puedan entrar en juego otras perspectivas para valorar el dolor, como la perspectiva de lo sagrado a que se refieren estas reflexiones, no se considera que aporta nada nuevo.

En el artículo de K. Rahner «Pasión y Ascesis», al que más arriba me he referido, aparece un punto de vista muy distinto. Diferencia él en primer lugar, antes de tratar sobre la ascesis cristiana, tres formas de buscar o querer el dolor que en la humanidad habrían existido asociados a empeños relativos a lo sagrado. Las llama ascética moral, ascética mística y ascética cultual. Entiende por ascética moral aquellas prácticas penitenciales o dolorosas que se han solido cultivar como entrenamiento y vigorización de la personalidad psicológica de los creyentes de diversas religiones, en orden a conseguir el autodominio que a uno le aportara más plena libertad para el acceso a lo santo. Con razón observa Rahner que en realidad algo parecido se practica en función de muy distintos empeños individuales y sociales, por ejemplo en la formación de deportistas o de cuerpos policiales de élite. Podemos añadir aquí que nadie llama dolorismo a la autodisciplina de los deportistas.

Por ascética mística entiende Rahner las prácticas de vaciamiento, sobre todo cultivadas en religiones orientales, que de muchas maneras implican o comprenden privaciones y dolor. Es curioso que lo que en ellas encuentra Rahner de rechazable no es nada relacionado con la cuestión misma del dolor, sino la creencia a su juicio implicada en esa ascética mística, según la cual alguna acción humana puede forzar el acercamiento a la divinidad. Esta parte del texto, por lo tanto, no nos ilustra sobre cómo concibe Rahner el enfrentamiento personal con el dolor.

Por ascética cultual entiende Rahner las privaciones y ritos dolorosos a que en antiguas religiones debían someterse muchas veces los que iban a participar en determinados cultos, sobre todo los oficiantes. Pero en la valoración de esas prácticas por Rahner no hallamos tampoco nada que nos instruya sobre la confrontación con el dolor. Él ve de nuevo en ellas un empeño por desbordar la vida profana y acceder al ámbito de lo sagrado, y vuelve a valorar ese empeño a la luz de la teología de la gracia: las consideraría rechazables si con ellas quisiera forzarse el acceso a lo sagrado, pero no las rechazaría si, como supuestamente ocurriría en la ascesis cristiana, se dejara completamente en las manos de Dios el resultado del empeño. 
¿Y que tendría la ascesis cristiana, fuera de no pretender manipular a Dios, que hiciera valer la búsqueda o aceptación libre de los sufrimientos no funcionales, es decir, de aquellos que no son adecuados para utilizarse con propósitos de adiestramiento utilitario, como los de la ascesis que Rahner llama moral?

Para explicarlo se vale Rahner de su reinterpretación teológico-existencial de las nociones de naturaleza, de persona y de muerte. Todos sabemos cómo miraba a la muerte el clásico existencialismo de Heidegger: ella sería la cuestión clave que escondidamente se nos haría presente en toda experiencia del tiempo y de la finitud; la tendencia del hombre-masa sería siempre el rehuir esa confrontación constante con la muerte, y al rehusar esa confrontación, caería en la inautenticidad y la pérdida de libertad: sería incapaz de tomarse a sí mismo como es, mortal, y de asumir en la vida y entre las cosas el lugar que le corresponde. $\mathrm{Y}$ aquí es donde entra en juego la comprensión rahneriana de los conceptos de naturaleza y persona: naturaleza sería en nosotros lo que nos viene «naturalmente» dado, lo que no configuramos nosotros optando libremente; en cambio la persona en nosotros sería lo que llegamos a ser asumiendo y configurando libremente nuestra naturaleza.

Teniendo esto en cuenta se entiende que para Rahner el dolor sea algo que afecta directa y primariamente a nuestra naturaleza y nos anuncia la muerte: con ello también nos pone decisivamente ante lo definitivo de nosotros mismos, y por tanto ante Dios. No tomar entonces libremente postura ante el dolor es rehuir la confrontación con las pasividades de nuestra naturaleza por las que se anuncia la muerte, es pretender conducirnos como si nos fuera dado vivir nuestro ser natural sin hacerlo personal, abdicando de nuestra llamada a la libertad. Pero si la postura que tomamos es de rebelión, y no de aceptación y acogida, entonces estamos queriendo afirmar soberbiamente nuestra libertad frente a las pasividades entre las cuales nos ha situado Dios y frente a la convocación de la muerte que nos pone ante Él. Por eso el único proceder cristianamente válido ante el dolor sería reconocer en él un mensaje de nuestra finitud, el cual, poniéndonos ante la muerte, nos pone ante los límites sagrados de nuestro ser personal. No solamente en los dolores inevitables, como serían los causados por enfermedades o por situaciones sociales forzosas, sino también en aquellos a que nos exponen las situaciones vocacionales libremente asumidas. En ambos casos el dolor sería destino que nos sitúa en la perspectiva de nuestra mortalidad y finitud. Y solamente en la aceptación y libre elaboración de ese límite del destino, se daría la verdadera aceptación del mundo y de Dios a la que como humanos estamos llamados. 
Estas bellas consideraciones de Rahner mantienen plenamente su validez más allá de los planteamientos existencialistas con que se explican. Porque en el fondo lo que hacen valer es un hecho: que los seres humanos estamos infiltrados de pasividad y no somos únicamente lo que queremos y decidimos. Tomar únicamente ante el dolor la postura de combatir activamente contra él, sin dejar lugar para asumirlo y aceptarlo, incluso despreciando o condenando ese empeño, es pretender conducirnos ante lo doloroso como quien puede afrontar la vida solamente con lo que hay en nosotros de iniciativa y poder, desconociendo lo demás. Como si nos fuera dado mirar hacia un futuro en que no nos afectaran nuestras pasividades e incluso organizarnos ya en función de ese futuro. Desde el punto de vista ético eso no puede valorarse sino como locura soberbia, y desde el punto de vista psicológico es autoengaño últimamente enfermizo. El papel que juega en Rahner la anticipación de la muerte que nos llama a tomar en cuenta nuestra finitud, es en realidad el papel que en la historia de la humanidad ha jugado, a la hora de la confrontación con el dolor, el reconocimiento y evocación de lo sagrado.

Pero estas reflexiones de Rahner, tan profundas desde el punto de vista religioso y humano, creo que no nos dan todas las dimensiones de las experiencias de dolor marcadas por la apertura hacia la potencia de lo sagrado. En efecto Rahner se fija por una parte sólo en los aspectos de lo sagrado que se nos manifiestan al confrontarnos con nuestra finitud y pasividad, por otra parte lo que él explana son los valores éticos iluminados a la luz de lo sagrado en el esfuerzo por asumir activa y rendidamente el dolor. Pero sabemos que lo sagrado se manifiesta de muchas otras maneras: por ejemplo dando ser y formas de ser, descubriendo horizontes nunca vistos, uniendo destinos y haciendo que se generen símbolos e imágenes nuevas del mundo.

Muchos psicoanalistas han abordado de modo insistente este tema de las nuevas simbólicas y formas de ser generadas por las grandes heridas, aunque para la mayoría de la gente es un extraño lenguaje el que ellos usan, como si les fuera mucho en no salirse de él. Para esos psicoanalistas pues, casi cualquier herida, incluso las imaginarias, pueden ser el acontecimiento fundante que da origen a la verdad del vivir. Pero con una condición: han de ser heridas que realmente castren, que mutilen de la idea de poderlo todo, o de tener que poderlo todo, a aquellos que las sufren. Y de esa idea maniáticamente fija de querer poderlo todo, incrustada en nosotros desde los orígenes de nuestra infancia, sólo las heridas nos librarían; la clase de heridas que se tienen en el abalanzarse hacia el objeto sacralizado del deseo. Sin la herida que hace entrar en crisis a lo sacralizado nunca encontraríamos en la vida nuestro sitio ni nuestro ser verdadero. 
No sé si puede decirse que en la experiencia dolorosa de lo sagrado, y en la experiencia del dolor donde lo sagrado se hace presencia, siempre se producirán heridas de esta clase; de las que hacen descubrir el sitio y la verdad de uno. Pero estoy seguro de que esto se ha procurado de muchas oscuras formas en la historia de la humanidad, de que de hecho ello ha ocurrido no excepcionalmente en diversas culturas, y que todavía además entre nosotros ocurre a veces, aunque no quiera decirse ni oírse. $\mathrm{Y}$ esto es algo distinto de lo que describe Rahner.

En algunos pueblos antiguos todos estos aspectos aparecían y tenían reconocimiento público. Para nosotros el caso más conocido es el de los judíos, entre los cuales el sueño de la herida de Jacob no era un un cuento sin importancia. Pues bien: según esa vieja narración Jacob, cuando se despierta del sueño en que había combatido con el ángel de Yahwé, lleva un nombre nuevo que es un ser nuevo; es entonces cuando funda un pueblo y marcha hacia su destino con una firmeza antes desconocida. Pero para todo esto le ha marcado la herida del ángel, por la que su caminar ha quedado inscrito en una historia diferente. Por la herida de la circuncisión se inscribirán luego los varones de Israel durante siglos en un destino que les dará sentido.

$\mathrm{Y}$ en conjunto no es absurdo que las heridas marquen, al contrario. Pero lo que más llama la atención es que en relación con lo sagrado el dolor marca sagradamente y crea un destino. Esto es lo que me parece más importante.

\section{Notas}

1 Cambridge University Press, 1970.

${ }^{2}$ Kröner, Stuttgart, 1960; p. 248s.

3 Como representativo de lo que actualmente se escribe por los teólogos acerca del dolor, he tomado los números monográficos que dedican a ese tema las revistas Concilium (1976: 119), Communio (1988:6), Teología y Catequesis (Enero-Marzo 1989) y Revista de Espiritualidad (Abril-Junio 1990).

4 En el número citado de la Revista de Espiritualidad.

5 Número citado de Concilium.

6 K. RAHNER, Escritos de Teología, III, p. 73-102. 